\title{
A New Technique to Compute Coupled Coincidence Points
}

\author{
Manish Jain, ${ }^{1}$ Neetu Gupta, ${ }^{2}$ and Sanjay Kumar ${ }^{3}$ \\ ${ }^{1}$ Department of Mathematics, Ahir College, Rewari 123401, India \\ ${ }^{2}$ HAS Department, YMCAUST, Faridabad 121006, India \\ ${ }^{3}$ Department of Mathematics, DCRUST, Murthal, Sonepat 131039, India \\ Correspondence should be addressed to Manish Jain; manish_261283@rediffmail.com
}

Received 2 October 2013; Accepted 30 October 2013; Published 29 January 2014

Academic Editors: Y. Feng and Z.-Y. Li

Copyright (C) 2014 Manish Jain et al. This is an open access article distributed under the Creative Commons Attribution License, which permits unrestricted use, distribution, and reproduction in any medium, provided the original work is properly cited.

We compute coupled coincidence points without assuming the condition of compatibility of the pair of maps and relaxing the continuity condition of both the maps. In fact, our technique improves the technique introduced by Sintunavarat et al. (2011) which was then used by Hussain et al. (2012) to obtain coupled coincidence points.

\section{Introduction and Preliminaries}

In recent times, the study of common fixed points of mappings under contractive conditions has developed rapidly. The Banach contraction principle [1] is an important tool in nonlinear analysis for solving problems concerning fixed points. Different authors extended and generalized this principle in various spaces by using more general contractive conditions in different ways. References [2-21] are some examples of these works. Nowadays, fixed point theory has been receiving much attention in partially ordered metric spaces, that is, metric spaces endowed with a partial ordering. Ran and Reurings [22] were the first to establish the results in this direction. The results were then extended by Nieto and Rodríguez-López [23] for nondecreasing mappings. The work in [23] was illustrated by showing the existence of unique solution for a first-order ordinary differential equation with periodic boundary conditions. Works noted in [24$30]$ are some examples in this direction.

Bhaskar and Lakshmikantham [31] developed some coupled fixed point theorems for a mapping satisfying mixed monotone property in partially ordered metric spaces. As an application, they discussed the existence and uniqueness of solution for a periodic boundary value problem. Lakshmikantham and Ćirić [32] extended the notion of mixed monotone property to mixed $g$-monotone property and generalized the results of Bhaskar and Lakshmikantham [31] by establishing the existence of coupled coincidence point results using a pair of commutative maps. Choudhury and Kundu [33] further generalized these results to a pair of compatible maps. Alotaibi and Alsulami [34] extended the results of Luong and Thuan [35] for a compatible pair. Recently, Haghi et al. [36] introduced a new technique that generalized several results present in the literature. This technique was further extended by Sintunavarat et al. [37] to obtain coupled coincidence points of mappings satisfying contractive conditions without the need for commutative condition in intuitionistic fuzzy normed spaces, which was then used by Hussain et al. [38] to generalize the results noted in [32-34] by replacing the assumption of compatibility (and hence of commutativity) and completeness of the space $X$ by assuming the completeness of the range subspace of the map g.

The purpose of this paper is to provide a technique that generalizes and improves the technique introduced by Sintunavarat et al. [37] and then used by Hussain et al. [38], in the sense that we are not first proving any result for a single mapping and then extending the obtained result for a pair of maps; rather, we give direct proof to obtain coupled coincidence points. In order to produce and compare our technique with the technique used by Hussain et al. [38], we use the same contractive conditions used by Hussain et al. [38] in their Theorems 2.9 and 2.11. Our technique is based on the iteration argument and provides a tool to generalize the coupled coincidence point results under different contractive conditions present in the literature of fixed point theory. 
We also provide an example that illustrates that the assumption of continuity of the mapping $g: X \rightarrow X$ in coupled coincidence point results is not necessary.

Now we give the following definitions which are useful in our study.

Definition 1 (see [31]). Let $(X, \leq)$ be a partially ordered set and $F: X \times X \rightarrow X$. The mapping $F$ is said to have the mixed monotone property if $F(x, y)$ is monotone nondecreasing in $x$ and monotone nonincreasing in $y$; that is, for any $x, y \in X$,

$$
\begin{aligned}
& x_{1}, x_{2} \in X, \quad x_{1} \leq x_{2} \text { implies } F\left(x_{1}, y\right) \leq F\left(x_{2}, y\right), \\
& y_{1}, y_{2} \in X, \quad y_{1} \leq y_{2} \text { implies } F\left(x, y_{1}\right) \geq F\left(x, y_{2}\right) .
\end{aligned}
$$

Definition 2 (see [32]). Let $(X, \leq)$ be a partially ordered set and $F: X \times X \rightarrow X$ and $g: X \rightarrow X$. We say $F$ has the mixed $g$-monotone property if $F$ is monotone $g$-nondecreasing in its first argument and is monotone $g$-nonincreasing in its second argument; that is, for any $x, y \in X$,

$$
\begin{aligned}
& x_{1}, x_{2} \in X, \quad g x_{1} \leq g x_{2} \\
& \text { implies } F\left(x_{1}, y\right) \leq F\left(x_{2}, y\right), \\
& y_{1}, y_{2} \in X, \quad g y_{1} \leq g y_{2} \\
& \text { implies } F\left(x, y_{1}\right) \geq F\left(x, y_{2}\right) .
\end{aligned}
$$

Definition 3 (see [31]). An element $(x, y) \in X \times X$ is called a coupled fixed point of the mapping $F: X \times X \rightarrow X$ if

$$
F(x, y)=x, \quad F(y, x)=y .
$$

Definition 4 (see [32]). An element $(x, y) \in X \times X$ is called a coupled coincidence point of the mappings $F: X \times X \rightarrow X$ and $g: X \rightarrow X$ if

$$
F(x, y)=g x, \quad F(y, x)=g y .
$$

Definition 5 (see [32]). Let $X$ be a nonempty set and $F: X \times$ $X \rightarrow X$ and $g: X \rightarrow X$. We say $F$ and $g$ are commutative if

$$
g(F(x, y))=F(g(x), g(y)),
$$

for all $x, y \in X$.

Definition 6 (see [33]). The mappings $F: X \times X \rightarrow X$ and $g: X \rightarrow X$ are said to be compatible if

$$
\begin{aligned}
& \lim _{n \rightarrow \infty} d\left(g F\left(x_{n}, y_{n}\right), F\left(g x_{n}, g y_{n}\right)\right)=0, \\
& \lim _{n \rightarrow \infty} d\left(g F\left(y_{n}, x_{n}\right), F\left(g y_{n}, g x_{n}\right)\right)=0,
\end{aligned}
$$

whenever $\left\{x_{n}\right\}$ and $\left\{y_{n}\right\}$ are sequences in $X$ such that $\lim _{n \rightarrow \infty} F\left(x_{n}, y_{n}\right)=\lim _{n \rightarrow \infty} g x_{n}=x$ and $\lim _{n \rightarrow \infty} F\left(y_{n}, x_{n}\right)=$ $\lim _{n \rightarrow \infty} g y_{n}=y$ for some $x, y \in X$.

Now we state a lemma which will be an important and powerful tool for us in computing the coupled coincidence points without assuming the condition of commutativity or minimal commutativity of the pair of maps and assuming subspace to be complete instead of completeness of the space.
Lemma 7 (see [36]). Let $X$ be a nonempty set and $g: X \rightarrow X$ a mapping. Then there exists a subset $E \subseteq X$ such that $g(E)=$ $g(X)$ and the mapping $g: E \rightarrow X$ is one-to-one.

\section{Main Results}

We now give our technique and improve Theorem 2.9 proved in [38].

Theorem 8. Let $(X, \leq, d)$ be a partially ordered metric space. Assume there is a function $\varphi:[0,+\infty) \rightarrow[0,+\infty)$ with $\varphi(t)<t$ and $\lim _{r \rightarrow t+} \varphi(r)<t$ for each $t>0$ and also suppose $F: X \times X \rightarrow X$ and $g: X \rightarrow X$ are such that $g(X)$ is complete and $F$ has the mixed $g$-monotone property and

$$
\begin{aligned}
& d(F(x, y), F(u, v)) \\
& \quad \leq \varphi\left(\frac{d(g(x), g(u))+d(g(y), g(v))}{2}\right)
\end{aligned}
$$

for all $x, y, u, v \in X$ for which $g(x) \leq g(u)$ and $g(y) \geq g(v)$. Suppose $F(X \times X) \subseteq g(X)$, and also suppose either

(a) $F$ and $g$ are continuous or

(b) X has the following property:

(i) if a nondecreasing sequence $\left\{x_{n}\right\} \rightarrow x$, then $x_{n} \leq$ $x, \forall n$,

(ii) if a nonincreasing sequence $\left\{y_{n}\right\} \rightarrow y$, then $y \leq$ $y_{n}, \forall n$.

If there exist two elements $x_{0}, y_{0} \in X$ such that $g x_{0} \leq$ $F\left(x_{0}, y_{0}\right)$ and $g y_{0} \geq F\left(y_{0}, x_{0}\right)$, then there exist $x, y \in X$ such that

$$
g x=F(x, y), \quad g y=F(y, x) ;
$$

that is, $F$ and $g$ have a coupled coincidence point.

Proof. Let $x_{0}, y_{0} \in X$ such that $g x_{0} \leq F\left(x_{0}, y_{0}\right), g y_{0} \geq$ $F\left(y_{0}, x_{0}\right)$. Since $F(X \times X) \subseteq g(X)$, we can choose $x_{1}, y_{1} \in X$ such that $g x_{1}=F\left(x_{0}, y_{0}\right), g y_{1}=F\left(y_{0}, x_{0}\right)$. Again we can choose $x_{2}, y_{2} \in X$ such that $g x_{2}=F\left(x_{1}, y_{1}\right), g y_{2}=F\left(y_{1}, x_{1}\right)$.

Continuing this process, we can construct sequences $\left\{g x_{n}\right\}$ and $\left\{g y_{n}\right\}$ in $X$ such that

$$
\begin{array}{r}
g x_{n+1}=F\left(x_{n}, y_{n}\right), \quad g y_{n+1}=F\left(y_{n}, x_{n}\right), \\
\forall n \geq 0 .
\end{array}
$$

We shall prove for all $n \geq 0$ that

$$
g x_{n} \leq g x_{n+1}, \quad g y_{n} \geq g y_{n+1} .
$$

Since $g x_{0} \leq F\left(x_{0}, y_{0}\right)$ and $g y_{0} \geq F\left(y_{0}, x_{0}\right), g x_{1}=F\left(x_{0}, y_{0}\right)$, and $g y_{1}=F\left(y_{0}, x_{0}\right)$, we have $g x_{0} \leq g x_{1}, g y_{0} \geq g y_{1}$; that is, (10) hold for $n=0$.

Suppose that (10) hold for some $n>0$; that is, $g x_{n} \leq$ $g x_{n+1}, g y_{n} \geq g y_{n+1}$. Since $F$ has the mixed $g$-monotone property, by (9), we have

$$
\begin{aligned}
& g x_{n+1}=F\left(x_{n}, y_{n}\right) \leq F\left(x_{n+1}, y_{n}\right) \leq F\left(x_{n+1}, y_{n+1}\right)=g x_{n+2}, \\
& g y_{n+1}=F\left(y_{n}, x_{n}\right) \geq F\left(y_{n+1}, x_{n}\right) \geq F\left(y_{n+1}, x_{n+1}\right)=g y_{n+2} ;
\end{aligned}
$$


that is,

$$
g x_{n+1} \leq g x_{n+2}, \quad g y_{n+1} \geq g y_{n+2} .
$$

Then by mathematical induction, it follows that (10) hold for all $n \geq 0$.

If for some $n \geq 0$, we have $\left(g x_{n+1}, g y_{n+1}\right)=\left(g x_{n}, g y_{n}\right)$, then $F\left(x_{n}, y_{n}\right)=g x_{n}$ and $F\left(y_{n}, x_{n}\right)=g y_{n}$; that is, $F$ and $g$ have a coupled coincidence point. So now onwards, we suppose $\left(g x_{n+1}, g y_{n+1}\right) \neq\left(g x_{n}, g y_{n}\right)$ for all $n \geq 0$; that is, we suppose that either $g x_{n+1}=F\left(x_{n}, y_{n}\right) \neq g x_{n}$ or $g y_{n+1}=F\left(y_{n}\right.$, $\left.x_{n}\right) \neq g y_{n}$.

Now following the steps of Theorem 2.1 [33], it is easy to show that the sequences $\left\{g x_{n}\right\}$ and $\left\{g y_{n}\right\}$ are Cauchy sequences. Since $g(X)$ is complete, there exist $x, y \in X$ such that

$$
\begin{aligned}
& \lim _{n \rightarrow \infty} F\left(x_{n}, y_{n}\right)=\lim _{n \rightarrow \infty} g\left(x_{n}\right)=g x, \\
& \lim _{n \rightarrow \infty} F\left(y_{n}, x_{n}\right)=\lim _{n \rightarrow \infty} g\left(y_{n}\right)=g y .
\end{aligned}
$$

We now show that $g x=F(x, y)$ and $g y=F(y, x)$.

Suppose that assumption (a) holds.

Now, using Lemma 7, there exists a subset $E \subseteq X$ such that $g(E)=g(X)$ and the mapping $g: E \rightarrow X$ is one-toone. Let us define a mapping $G: g(E) \times g(E) \rightarrow X$ by

$$
G(g a, g b)=F(a, b)
$$

for all $g a, g b \in g(E)=g(X)$

Since $g$ is one-to-one on $E$, so the map $G$ is well-defined. Using (13) and (14), we get

$$
\begin{gathered}
\lim _{n \rightarrow \infty} G\left(g x_{n}, g y_{n}\right)=\lim _{n \rightarrow \infty} F\left(x_{n}, y_{n}\right) \\
=\lim _{n \rightarrow \infty} g\left(x_{n}\right)=g x, \\
\lim _{n \rightarrow \infty} G\left(g y_{n}, g x_{n}\right)=\lim _{n \rightarrow \infty} F\left(y_{n}, x_{n}\right)=\lim _{n \rightarrow \infty} g\left(y_{n}\right)=g y .
\end{gathered}
$$

Since $F$ and $g$ are continuous, $G$ is also continuous. Then, on using (15) we get

$$
G(g x, g y)=g x, \quad G(g y, g x)=g y .
$$

Using (14) and (16), we get

$$
F(x, y)=g x, \quad F(y, x)=g y .
$$

Finally, suppose that (b) holds. By (10) and (13), we have that $\left\{g x_{n}\right\}$ is a nondecreasing sequence, $g x_{n} \rightarrow g x$ as $n \rightarrow \infty$, and $\left\{g y_{n}\right\}$ is a nonincreasing sequence, $g y_{n} \rightarrow g y$ as $n \rightarrow$ $\infty$. Hence, by assumption, we have for all $n \geq 0$ that

$$
g x_{n} \leq g x, \quad g y \leq g y_{n} .
$$

If $g x_{n}=g x$ and $g y_{n}=g y$ for some $n \geq 0$, then $g x=g x_{n} \leq$ $g x_{n+1} \leq g x=g x_{n}$ and $g y_{n}=g y \leq g y_{n+1} \leq g y_{n}=g y$, which implies that $g x_{n}=g x_{n+1}=F\left(x_{n}, y_{n}\right)$ and $g y_{n}=g y_{n+1}=$ $F\left(y_{n}, x_{n}\right)$; that is, $\left(x_{n}, y_{n}\right)$ is a coupled coincidence point of
$F$ and $g$. Then, we suppose that $\left(g x_{n}, g y_{n}\right) \neq(g x, g y)$ for all $n \geq 0$. Then using (7) for (18), we get

$$
\begin{aligned}
& d\left(F\left(x_{n}, y_{n}\right), F(x, y)\right) \\
& \quad \leq \varphi\left(\frac{d\left(g\left(x_{n}\right), g(x)\right)+d\left(g\left(y_{n}\right), g(y)\right)}{2}\right) .
\end{aligned}
$$

By triangle inequality, we have

$$
\begin{aligned}
& d(g x, F(x, y)) \\
& \quad \leq\left\{d\left(g x, F\left(x_{n}, y_{n}\right)\right)+d\left(F\left(x_{n}, y_{n}\right), F(x, y)\right)\right\} .
\end{aligned}
$$

Inserting (19) in (20) and letting $n \rightarrow \infty$, we get

$$
\begin{aligned}
d(g x, F(x, y)) & \\
\leq \lim _{n \rightarrow \infty} & \left\{d\left(g x, F\left(x_{n}, y_{n}\right)\right)\right. \\
& \left.+\varphi\left(\frac{d\left(g\left(x_{n}\right), g(x)\right)+d\left(g\left(y_{n}\right), g(y)\right)}{2}\right)\right\} .
\end{aligned}
$$

Using (13) and the property of $\varphi$-function we obtain $d(g x, F(x, y)) \leq 0$.

That is, $g(x)=F(x, y)$ and, similarly, it can be shown that $g(y)=F(y, x)$.

Thus we proved that $F$ and $g$ have a coupled coincidence point in $X$. This completes the proof.

In order to improve Theorem 2.11 proved in [38], we need the following.

As in $[34,35]$, denote by $\Phi$ the class of all functions $\emptyset$ : $[0, \infty) \rightarrow[0, \infty)$ which satisfy the following conditions:

(1) $\emptyset$ is continuous and nondecreasing;

(2) $\emptyset(t)=0$ if and only if $t=0$;

(3) $\emptyset(t+s) \leq \emptyset(t)+\emptyset(s)$.

Also, denote by $\Psi$ the class of all functions $\psi:[0, \infty) \rightarrow$ $(0, \infty)$ which satisfy $\lim _{n \rightarrow \infty} \psi(t)>0$ for $r>0$ and $\lim _{t \rightarrow 0^{+}} \psi(t)=0$.

Now, we improve Theorem 2.11 proved in [38].

Theorem 9. Let $(X, \leq, d)$ be a partially ordered metric space and $F: X \times X \rightarrow X$ and $g: X \rightarrow X$ mappings such that $F$ has mixed $g$-monotone property on $X$. Suppose that there exist two elements $x_{0}, y_{0} \in X$ such that $g x_{0} \leq F\left(x_{0}, y_{0}\right)$ and $g y_{0} \geq F\left(y_{0}, x_{0}\right)$. Suppose there exist $\emptyset \in \Phi$ and $\psi \in \Psi$ such that

$$
\begin{aligned}
\emptyset( & d(F(x, y), F(u, v))) \\
\leq & \frac{1}{2} \emptyset(d(g x, g u)+d(g y, g v)) \\
& -\psi\left(\frac{d(g x, g u)+d(g y, g v)}{2}\right)
\end{aligned}
$$

for all $x, y, u, v \in X$ for which $g(x) \leq g(u)$ and $g(y) \geq g(v)$. Supposing $F(X \times X) \subseteq g(X), g(X)$ is complete subspace of $X$ and also suppose either 
(a) F and $g$ are continuous or

(b) X has the following property:

(i) if a nondecreasing sequence $\left\{x_{n}\right\} \rightarrow x$, then $x_{n} \leq$ $x, \forall n$,

(ii) if a nonincreasing sequence $\left\{y_{n}\right\} \rightarrow y$, then $y \leq$ $y_{n}, \forall n$.

Then there exist $x, y \in X$ such that

$$
g x=F(x, y), \quad g y=F(y, x) ;
$$

that is, $F$ and $g$ have a coupled coincidence point.

Proof. Let $x_{0}, y_{0} \in X$ such that $g x_{0} \leq F\left(x_{0}, y_{0}\right), g y_{0} \geq$ $F\left(y_{0}, x_{0}\right)$. Since $F(X \times X) \subseteq g(X)$ and $F$ satisfy $g$-monotone property, then, as in the proof of Theorem 8 , we can construct sequences $\left\{g x_{n}\right\}$ and $\left\{g y_{n}\right\}$ in $X$ such that

$$
\begin{array}{r}
g x_{n+1}=F\left(x_{n}, y_{n}\right), \quad g y_{n+1}=F\left(y_{n}, x_{n}\right), \\
\forall n \geq 0, \\
g x_{n} \leq g x_{n+1}, \quad g y_{n} \geq g y_{n+1} .
\end{array}
$$

Further, we have to assume $\left(g x_{n+1}, g y_{n+1}\right) \neq\left(g x_{n}, g y_{n}\right)$ for all $n \geq 0$; that is, we assume that either $g x_{n+1}=F\left(x_{n}, y_{n}\right) \neq g x_{n}$ or $g y_{n+1}=F\left(y_{n}, x_{n}\right) \neq g y_{n}$; otherwise $F$ and $g$ have a coupled coincidence point.

Then, as in the proof of Theorem 3.1 [34], it is easy to show that the sequences $\left\{g x_{n}\right\}$ and $\left\{g y_{n}\right\}$ are Cauchy sequences. Since $g(X)$ is complete, there exist $x, y \in X$ such that

$$
\begin{aligned}
& \lim _{n \rightarrow \infty} F\left(x_{n}, y_{n}\right)=\lim _{n \rightarrow \infty} g\left(x_{n}\right)=g x, \\
& \lim _{n \rightarrow \infty} F\left(y_{n}, x_{n}\right)=\lim _{n \rightarrow \infty} g\left(y_{n}\right)=g y .
\end{aligned}
$$

We now show that $g x=F(x, y)$ and $g y=F(y, x)$.

Suppose that assumption (a) holds.

Now, using Lemma 7, there exists a subset $E \subseteq X$ such that $g(E)=g(X)$ and the mapping $g: E \rightarrow X$ is one-toone. Let us define a mapping $G: g(E) \times g(E) \rightarrow X$ by

$$
G(g a, g b)=F(a, b)
$$

for all $g a, g b \in g(E)=g(X)$.

Since $g$ is one-to-one on $E$, so the map $G$ is well-defined. Using (26)-(27), we get

$$
\begin{aligned}
\lim _{n \rightarrow \infty} G\left(g x_{n}, g y_{n}\right) & =\lim _{n \rightarrow \infty} F\left(x_{n}, y_{n}\right) \\
& =\lim _{n \rightarrow \infty} g\left(x_{n}\right)=g x, \\
\lim _{n \rightarrow \infty} G\left(g y_{n}, g x_{n}\right) & =\lim _{n \rightarrow \infty} F\left(y_{n}, x_{n}\right) \\
& =\lim _{n \rightarrow \infty} g\left(y_{n}\right)=g y .
\end{aligned}
$$

Since $F$ and $g$ are continuous, $G$ is also continuous. Then, on using (28), we get

$$
G(g x, g y)=g x, \quad G(g y, g x)=g y .
$$

Using (27) and (29), we get

$$
F(x, y)=g x, \quad F(y, x)=g y .
$$

Finally, suppose that (b) holds. Then using (25) and (26), we have for all $n \geq 0$ that

$$
g x_{n} \leq g x, \quad g y \leq g y_{n} .
$$

If $g x_{n}=g x$ and $g y_{n}=g y$ for some $n \geq 0$, then $g x=g x_{n} \leq$ $g x_{n+1} \leq g x=g x_{n}$ and $g y_{n}=g y \leq g y_{n+1} \leq g y_{n}=g y$, which implies that $g x_{n}=g x_{n+1}=F\left(x_{n}, y_{n}\right)$ and $g y_{n}=g y_{n+1}=$ $F\left(y_{n}, x_{n}\right)$; that is, $\left(x_{n}, y_{n}\right)$ is a coupled coincidence point of $F$ and $g$. Then, we suppose that $\left(g x_{n}, g y_{n}\right) \neq(g x, g y)$ for all $n \geq 0$. Now, using (22) for (31), we get

$$
\begin{aligned}
\emptyset( & \left.d\left(F\left(x_{n}, y_{n}\right), F(x, y)\right)\right) \\
\leq & \frac{1}{2} \emptyset\left(d\left(g x_{n}, g x\right)+d\left(g y_{n}, g y\right)\right) \\
& -\psi\left(\frac{d\left(g x_{n}, g x\right)+d\left(g y_{n}, g y\right)}{2}\right) .
\end{aligned}
$$

By triangle inequality, we have

$$
\begin{aligned}
& d(g x, F(x, y)) \\
& \quad \leq\left\{d\left(g x, F\left(x_{n}, y_{n}\right)\right)+d\left(F\left(x_{n}, y_{n}\right), F(x, y)\right)\right\} .
\end{aligned}
$$

Using the properties of $\emptyset$, we get

$$
\begin{aligned}
\emptyset( & d(g x, F(x, y))) \\
\leq & \emptyset\left(d\left(g x, F\left(x_{n}, y_{n}\right)\right)+d\left(F\left(x_{n}, y_{n}\right), F(x, y)\right)\right) \\
\leq & \emptyset\left(d\left(g x, F\left(x_{n}, y_{n}\right)\right)\right) \\
& +\emptyset\left(d\left(F\left(x_{n}, y_{n}\right), F(x, y)\right)\right) .
\end{aligned}
$$

Inserting (32) in (34), we get

$$
\begin{aligned}
\emptyset( & d(g x, F(x, y))) \\
\leq & \emptyset\left(d\left(g x, F\left(x_{n}, y_{n}\right)\right)\right) \\
& +\frac{1}{2} \emptyset\left(d\left(g x_{n}, g x\right)+d\left(g y_{n}, g y\right)\right) \\
& -\psi\left(\frac{d\left(g x_{n}, g x\right)+d\left(g y_{n}, g y\right)}{2}\right) .
\end{aligned}
$$

Letting $n \rightarrow \infty$, we get

$$
\begin{aligned}
& \emptyset(d(g x, F(x, y))) \\
& \leq \lim _{n \rightarrow \infty} \emptyset\left(d\left(g x, F\left(x_{n}, y_{n}\right)\right)\right) \\
& \quad+\frac{1}{2} \lim _{n \rightarrow \infty} \emptyset\left(d\left(g x_{n}, g x\right)+d\left(g y_{n}, g y\right)\right) \\
& \quad-\lim _{n \rightarrow \infty} \psi\left(\frac{d\left(g x_{n}, g x\right)+d\left(g y_{n}, g y\right)}{2}\right) .
\end{aligned}
$$


Using (26) and properties of $\emptyset$ and $\psi$, it follows that $\emptyset(d(g x, F(x, y)))=0$; thus $d(g x, F(x, y))=0$. Hence $g x=$ $F(x, y)$. Similarly, we can show that $g y=F(y, x)$. Thus we proved $F$ and $g$ have a coupled coincidence point.

Remark 10. (i) The technique of Sintunavarat et al. [37] used by Hussain et al. [38] first requires to prove the result for a single mapping and, then, extends the obtained result to a pair of mappings but our technique yields a direct method to compute coupled coincidence points for a pair of mappings.

(ii) Case (b) of Theorems 8 and 9 proved in this paper not only relaxes the continuity assumption of the mapping $F$ but also relaxes the continuity of the mapping $g$ which has not been relaxed in Case (b) of Theorems 2.9 and 2.11 of Hussain et al. [38].

In view of this discussion, we can conclude that our technique improves the technique used in $[37,38]$.

Next, we give some examples in support of our results.

Example 11. Let $X=R$, endowed with usual metric $d$ and usual order $\leq$. Then $(X, \leq, d)$ is a partially ordered metric space. Define the mappings $F: X \times X \rightarrow X$ and $g: X \rightarrow X$ by $F(x, y)=2$ for all $(x, y) \in X \times X$ and $g(x)=x-2$ for all $x \in X$.

Clearly the mappings $F$ and $g$ are not commutative, since $g(F(x, y))=0 \neq 2=F(g x, g y)$ and $g(F(y, x))=0 \neq 2=$ $F(g y, g x)$. Next, we show that $F$ and $g$ are not compatible. For, let $\left\{x_{n}\right\}=\{4+1 / n\}$ and $\left\{y_{n}\right\}=\{4-1 / n\}$ be two sequences in $X$; then

$$
\begin{array}{ll}
\lim _{n \rightarrow \infty} F\left(x_{n}, y_{n}\right)=2, & \lim _{n \rightarrow \infty} g\left(x_{n}\right)=2, \\
\lim _{n \rightarrow \infty} F\left(y_{n}, x_{n}\right)=2, & \lim _{n \rightarrow \infty} g\left(y_{n}\right)=2 .
\end{array}
$$

Further, it follows that

$$
\begin{aligned}
& d\left(g F\left(x_{n}, y_{n}\right), F\left(g x_{n}, g y_{n}\right)\right) \nrightarrow 0 \text { as } n \rightarrow \infty, \\
& d\left(g F\left(x_{n}, y_{n}\right), F\left(g x_{n}, g y_{n}\right)\right) \nrightarrow 0 \text { as } n \rightarrow \infty .
\end{aligned}
$$

Hence, the mappings $F$ and $g$ are not compatible. Simple calculations show that $F(X \times X)=\{2\} \subseteq g(X)=R$, the space $g(X)$ is complete, the mappings $g$ and $F$ are continuous, and $F$ has the mixed $g$-monotone property. Moreover, there exist $x_{0}=2$ and $y_{0}=5$ with $g(2)=0 \leq 2=F(2,5)$ and $g(5)=3 \geq 2=F(5,2)$. Further, by the choice of function $F$, the contractive conditions (7) and (22) are trivial. Therefore, all the conditions of Theorems 8 and 9 are satisfied; hence the mappings $F$ and $g$ have a coupled coincidence point in $X \times X$. Indeed, the point $(4,4)$ is a coupled coincidence point of $F$ and $g$.

Example 12. Let $X=[0,1]$, endowed with usual metric $d$ and usual order $\leq$. Then $(X, \leq, d)$ is a partially ordered metric space. Also, $X$ satisfies the property taken in Case (b) of
Theorems 8 and 9. Define the mappings $F: X \times X \rightarrow X$ and $g: X \rightarrow X$ by

$$
\begin{gathered}
F(x, y)=0.5 \quad \forall(x, y) \in X \times X, \\
g(x)= \begin{cases}0.4 & \text { if } 0 \leq x<0.6, \\
x-0.3 & \text { if } 0.6 \leq x \leq 1\end{cases}
\end{gathered}
$$

Since $g(F(x, y))=g(0.5)=0.4 \neq 0.5=F(g x, g y)$ for all $x$, $y \in X$, the mappings $F$ and $g$ are not commutative. Next we show that $F$ and $g$ are not compatible. For this, let us consider the sequences $\left\{x_{n}\right\}=\{0.8+1 / n\}$ and $\left\{y_{n}\right\}=\{0.8-1 / n\}$, for all $n \geq 5$; then

$$
\begin{array}{ll}
\lim _{n \rightarrow \infty} F\left(x_{n}, y_{n}\right)=0.5, & \lim _{n \rightarrow \infty} g\left(x_{n}\right)=0.5, \\
\lim _{n \rightarrow \infty} F\left(y_{n}, x_{n}\right)=0.5, & \lim _{n \rightarrow \infty} g\left(y_{n}\right)=0.5 .
\end{array}
$$

Also, it follows that

$$
\begin{aligned}
& \lim _{n \rightarrow \infty} d\left(g F\left(x_{n}, y_{n}\right), F\left(g x_{n}, g y_{n}\right)\right)=0.1 \neq 0, \\
& \lim _{n \rightarrow \infty} d\left(g F\left(y_{n}, x_{n}\right), F\left(g y_{n}, g x_{n}\right)\right)=0.1 \neq 0 .
\end{aligned}
$$

Hence, the mappings $F$ and $g$ are not compatible. Clearly $F(X \times X) \subseteq g(X)$ and $g(X)$ is complete. Also, the mapping $g$ is not continuous and $F$ has mixed $g$-monotone property. Further, there exist $x_{0}=0.2$ and $y_{0}=0.9$ such that $g\left(x_{0}\right)=$ $g(0.2)=0.4 \leq 0.5=F(0.2,0.9)=F\left(x_{0}, y_{0}\right)$ and $g\left(y_{0}\right)=$ $g(0.9)=0.6 \geq 0.5=F(0.9,0.2)=F\left(y_{0}, x_{0}\right)$. It is easy to check that the contractive conditions involved in Theorems 8 and 9 are obvious. Hence, all the conditions of Theorems 8 and 9 are satisfied; thus $F$ and $g$ have a coupled coincidence point in $X \times X$. Indeed, the point $(0.8,0.8)$ is a coupled coincidence point of $F$ and $g$.

Remark 13. Theorems 2.9 and 2.11 in [38] cannot be applied to Example 12 since $g$ is not continuous but using Theorems 8 and 9 we obtained coupled coincidence points under the same contractive conditions as used in [38, Theorems 2.9 and 2.11]. This shows that the results presented in this paper are true generalizations of the results in [38].

\section{Conflict of Interests}

The authors declare that there is no conflict of interests regarding the publication of this paper.

\section{References}

[1] S. Banach, "Surles operations dans les ensembles et leur application aux equations itegrales," Fundamenta Mathematicae, vol. 3, pp. 133-181, 1922.

[2] M. Abbas and G. Jungck, "Common fixed point results for noncommuting mappings without continuity in cone Metric spaces," Journal of Mathematical Analysis and Applications, vol. 341, no. 1, pp. 416-420, 2008.

[3] M. Abbas and B. E. Rhoades, "Common fixed point results for noncommuting mappings without continuity in generalized Metric spaces," Applied Mathematics and Computation, vol. 215, no. 1, pp. 262-269, 2009. 
[4] T. Abdeljawad, "Completion of cone Metric spaces," Hacettepe Journal of Mathematics and Statistics, vol. 39, no. 1, pp. 67-74, 2010.

[5] I. Beg and M. Abbas, "Coincidence point and invariant approximation for mappings satisfying generalized weak contractive condition," Fixed Point Theory and Applications, vol. 2006, Article ID 74503, 2006.

[6] T. G. Bhaskar and V. Lakshmikantham, "Fixed point theorems in partially ordered Metric spaces and applications," Nonlinear Analysis: Theory, Methods and Applications, vol. 65, no. 7, pp. 1379-1393, 2006.

[7] L. G. Haung and X. Zhang, "Cone Metric spaces and fixed point theorems of contractive mappings," Journal of Mathematical Analysis and Applications, vol. 332, pp. 1468-1476, 2007.

[8] G. Jungck, "Commuting maps and fixed points," The American Mathematical Monthly, vol. 83, pp. 261-263, 1976.

[9] G. Jungck, "Compatible mappings and common fixed points," International Journal of Mathematics and Mathematical Sciences, vol. 9, no. 4, pp. 771-779, 1986.

[10] G. Jungck, "Common fixed points for commuting and compatible maps on compacta," Proceedings of the American Mathematical Society, vol. 103, pp. 977-983, 1988.

[11] G. Jungck and N. Hussain, "Compatible maps and invariant approximations," Journal of Mathematical Analysis and Applications, vol. 325, no. 2, pp. 1003-1012, 2007.

[12] P. P. Murthy and K. Tas, "New common fixed point theorems of Gregus type for R-weakly commuting mappings in 2-Metric spaces," Hacettepe Journal of Mathematics and Statistics, vol. 38, pp. 285-291, 2009.

[13] R. P. Pant, "Common fixed points of noncommuting mappings," Journal of Mathematical Analysis and Applications, vol. 188, no. 2, pp. 436-440, 1994.

[14] V. Popa and M. Mocanu, "Altering distance and common fixed points under implicit relations," Hacettepe Journal of Mathematics and Statistics, vol. 38, no. 3, pp. 329-337, 2009.

[15] I. Şahin and M. Telci, "Fixed points of contractive mappings on complete cone Metric spaces," Hacettepe Journal of Mathematics and Statistics, vol. 38, no. 1, pp. 59-67, 2009.

[16] W. Shatanawi, "Some common coupled fixed point results in cone Metric spaces," International Journal of Mathematical Analysis, vol. 4, no. 48, pp. 2381-2388, 2010.

[17] W. Sintunavarat and P. Kumam, "Weak condition for generalized multi-valued (f, $\alpha, \beta)$-weak contraction mappings," Applied Mathematics Letters, vol. 24, no. 4, pp. 460-465, 2011.

[18] W. Sintunavarat and P. Kumam, "Common fixed point theorem for hybrid generalized multi-valued contraction mappings," Applied Mathematics Letters, vol. 25, no. 1, pp. 52-57, 2012.

[19] W. Sintunavarat and P. Kumam, "Common fixed point theorems for generalized JH-operator classes and invariant approximations," Journal of Inequalities and Applications, vol. 2011, article 67, 2011.

[20] W. Sintunavarat and P. Kumam, "Common fixed point theorem for cyclic generalized multi-valued contraction mappings," Applied Mathematics Letters, vol. 25, no. 11, pp. 1849-1855, 2012.

[21] H. Aydi, C. Vetro, W. Sintunavarat, and P. Kumam, "Coincidence and fixed points for contractions and cyclical contractionsin partial metric spaces," Fixed Point Theory and Applications, vol. 2012, article 124, 2012.

[22] A. C. M. Ran and M. C. B. Reurings, "A fixed point theorem in partially ordered sets and some applications to matrix equations," Proceedings of the American Mathematical Society, vol. 132, no. 5, pp. 1435-1443, 2004.
[23] J. J. Nieto and R. Rodríguez-López, "Existence and uniqueness of fixed point in partially ordered sets and applications to ordinary differential equations," Acta Mathematica Sinica, vol. 23, no. 12, pp. 2205-2212, 2007.

[24] R. P. Agarwal, M. A. El-Gebeily, and D. O’Regan, "Generalized contractions in partially ordered Metric spaces," Applied Analysis, vol. 87, pp. 1-8, 2008.

[25] I. Altun and H. Simsek, "Some fixed point theorems on ordered Metric spaces and application," Fixed Point Theory and Applications, vol. 2010, Article ID 621469, 17 pages, 2010.

[26] J. Harjani and K. Sadarangani, "Generalized contractions in partially ordered Metric spaces and applications to ordinary differential equations," Nonlinear Analysis: Theory, Methods and Applications, vol. 72, no. 3-4, pp. 1188-1197, 2010.

[27] Z. Kadelburg, M. Pavlović, and S. Radenović, "Common fixed point theorems for ordered contractions and quasicontractions in ordered cone Metric spaces," Computers and Mathematics with Applications, vol. 59, no. 9, pp. 3148-3159, 2010.

[28] S. Radenovi and Z. Kadelburg, "Generalized weak contractions in partially ordered Metric spaces," Computers and Mathematics with Applications, vol. 60, no. 6, pp. 1776-1783, 2010.

[29] W. Sintunavarat, Y. J. Cho, and P. Kumam, "Common fixed point theorems for c-distance in ordered cone Metric spaces," Computers and Mathematics with Applications, vol. 62, no. 4, pp. 1969-1978, 2011.

[30] A. Kaewkhao, W. Sintunavarat, and P. Kumam, "Common fixed point theorems for c-distance on cone Metric spaces," Journal of Nonlinear Analysis: Theory, Methods \& Applications, vol. 2012, Article ID jnaa-00137, 11 pages, 2012.

[31] M. Jain, K. Tas, B. E. Rhoades, and N. Gupta, "Coupled fixed point theorems for generalized symmetric contractions in partially ordered Metric spaces and applications," Journal of Computational Analysis and Applications, vol. 16, no. 3, pp. 438454, 2014.

[32] V. Lakshmikantham and L. Ćirić, "Coupled fixed point theorems for nonlinear contractions in partially ordered Metric spaces," Nonlinear Analysis: Theory, Methods and Applications, vol. 70, no. 12, pp. 4341-4349, 2009.

[33] B. S. Choudhury and A. Kundu, "A coupled coincidence point result in partially ordered Metric spaces for compatible mappings," Nonlinear Analysis: Theory, Methods and Applications, vol. 73, no. 8, pp. 2524-2531, 2010.

[34] A. Alotaibi and S. M. Alsulami, "Coupled coincidence points for monotone operators in partially ordered metric spaces," Fixed Point Theory and Applications, vol. 2011, article 44, 2011.

[35] N. V. Luong and N. X. Thuan, "Coupled fixed points in partially ordered Metric spaces and application," Nonlinear Analysis: Theory, Methods and Applications, vol. 74, no. 3, pp. 983-992, 2011.

[36] R. H. Haghi, S. Rezapour, and N. Shahzad, "Some fixed point generalizations are not real generalizations," Nonlinear Analysis: Theory, Methods and Applications, vol. 74, no. 5, pp. 1799-1803, 2011.

[37] W. Sintunavarat, Y. J. Cho, and P. Kumam, "Coupled coincidence point theorems for contractions without commutative condition in intuitionistic fuzzy normed spaces," Fixed Point Theory and Applications, vol. 2011, article 81, 2011.

[38] N. Hussain, A. Latif, and M. H. Shah, "Coupled and tripled coincidence point results without compatibility," Fixed Point Theory and Applications, vol. 2012, article 77, 2012. 


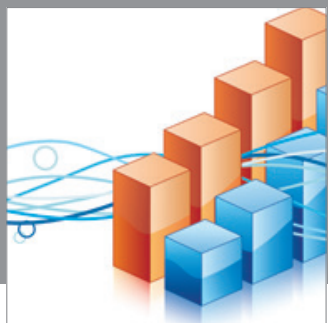

Advances in

Operations Research

mansans

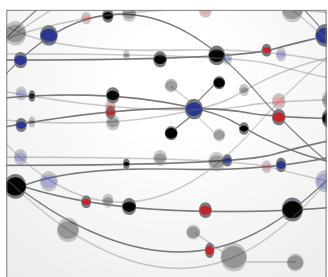

The Scientific World Journal
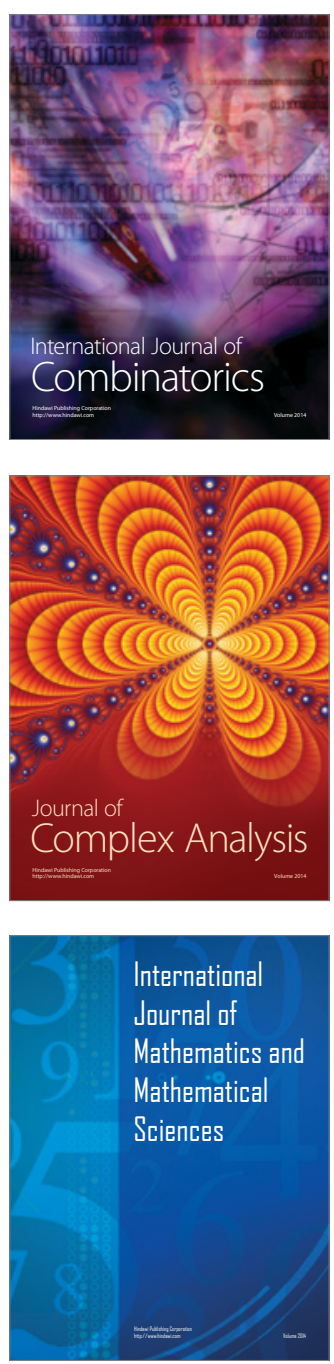
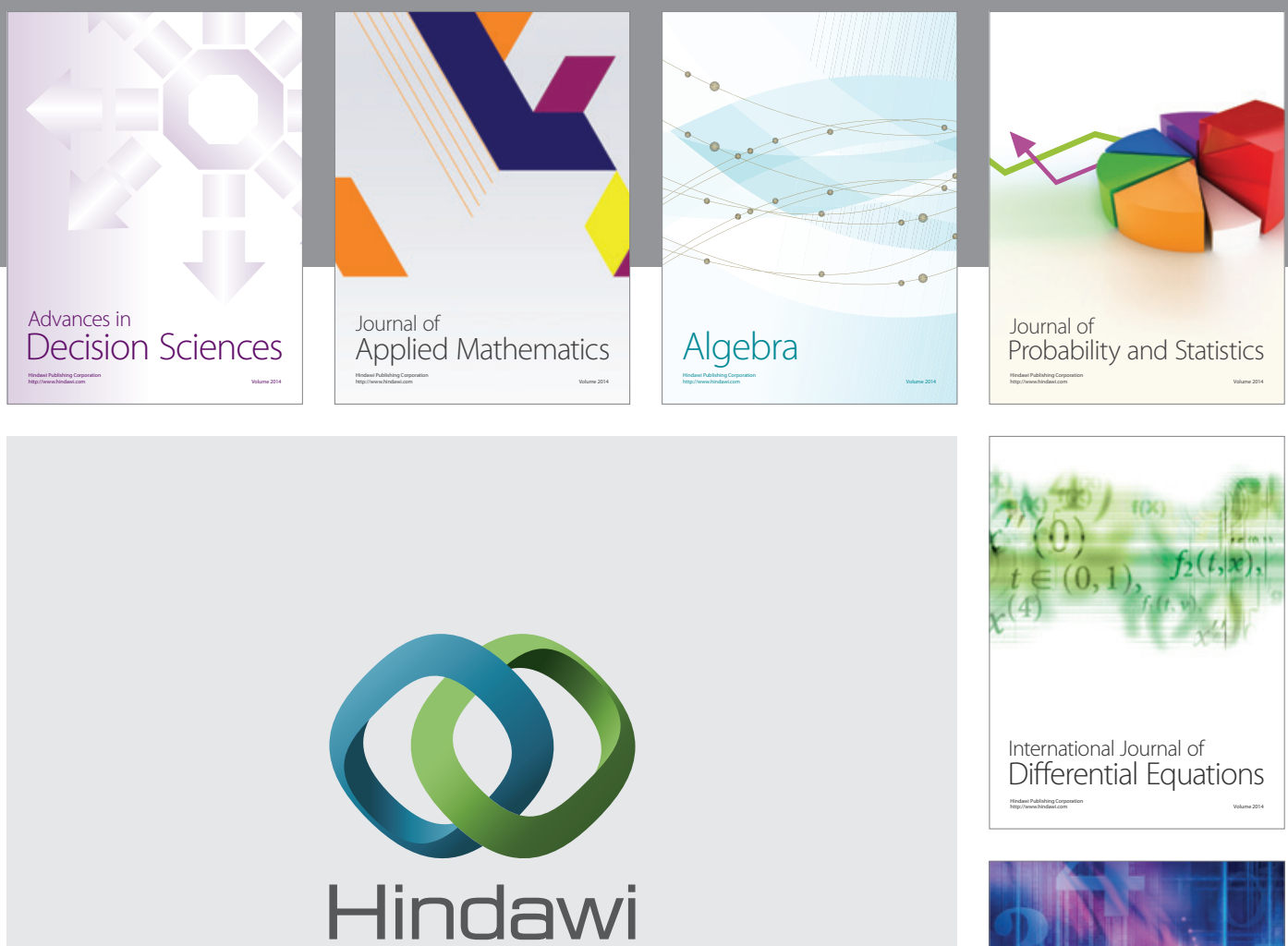

Submit your manuscripts at http://www.hindawi.com
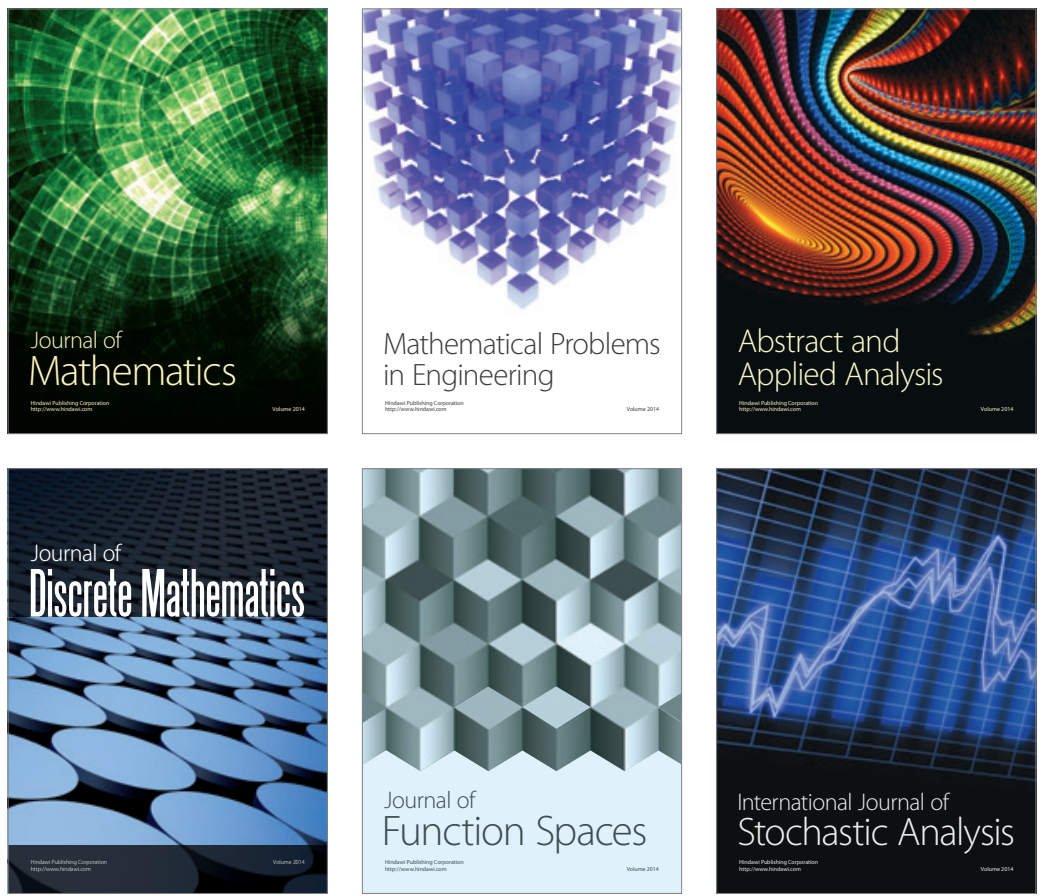

Journal of

Function Spaces

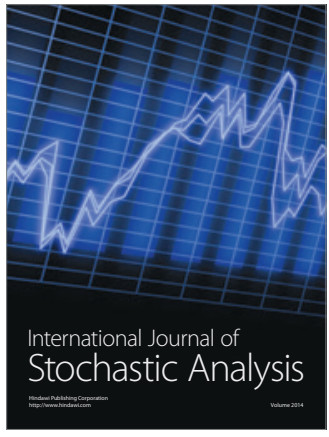

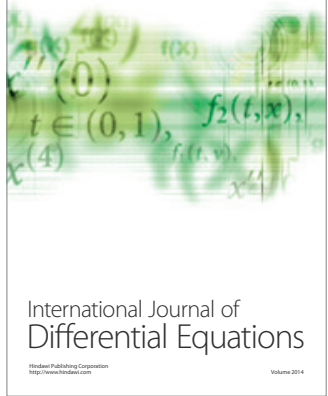
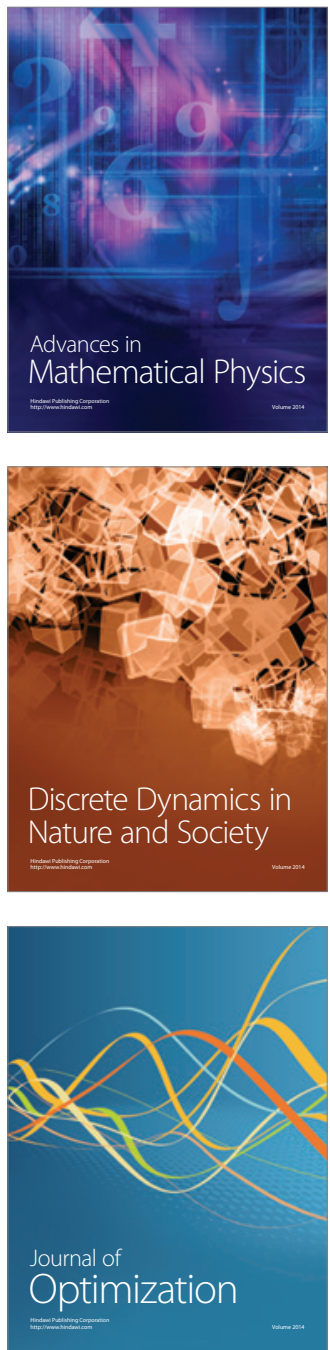